\title{
Mobile phone waste disposal willingness: A case of Shanghai, China
}

\author{
Yiwen Bian ${ }^{a}$, Miao $\mathrm{Hu}^{\mathrm{b}}$ and Yage Wang ${ }^{\mathrm{c}}$ \\ SHU-UTS SILC Business School, Shanghai University, Shanghai 201899, China \\ aywbian@shu.edu.cn, bhumiao0723@163.com, cjacobwang123@gmail.com
}

Keywords: Waste mobile phone, disposal willingness, influential factors.

\begin{abstract}
A large amount of waste mobile phone has been one of key environmental issues in China as well as the whole world. To improve the recycling rates of waste mobile phones, it is necessary to investigate the influential factors of its recycling. This paper examines the disposal willingness of waste mobile phones for young consumers in Shanghai city, China. To this end, four treatment ways, i.e., storage, recycling, discarding and donation, are considered. The results show that more consumers in Shanghai prefer storing their waste mobile phones rather than recycling them. The influential factors are identified based on the survey analysis and policy suggestions for enhancing waste mobile phone recycling rate are also provided.
\end{abstract}

\section{Introduction}

Mobile phone industry has experienced rapid progress in China in recent years. Nowadays, China has been the largest handset-producer and handset-consumer in the world. Ministry of Industry and Information Technology (MIIT) of China has reported that, up to January 2014, the number of mobile subscribers has been reached about 1.235 billion, which accounts for about one fourth that of the whole world. Due to the rapid introduction of new and improved technologies into mobile phones, coupled with consumers' increasing pursuit for new designs and functions such as cameras, music players and mobile-commerce, mobile phones have relatively short lifecycles and are increasingly seen as obsolete by many users within little over a year [1]. This perceived in-built obsolescence has led to the mass generation of waste mobile phones in China. There are appropriately 70 million mobile phones scraped every year before 2011 and this number is predicted to increase by $10 \%$ every year [2]. Large quantities of discarded waste mobile phones and accessories have represented a significant and growing problem with respect to waste electrical and electronic equipment (WEEE) [3]. The large amount of waste mobile phone has been one of key environmental issues in China.

In order to save resource and alleviate environment pollution resulted from WEEE, the Chinese central government has struggled to introduce laws, regulations and policies (e.g., Disposal of Waste Electrical and Electronic Equipment's) to manage WEEE [4]. However, the effective establishment and implement of relevant policies and regulations must depend on the willingness of consumers to participate in recycling and reuse activities. Otherwise, neither government policies nor participation by producers can be effectively put into practice. Therefore, it is necessary to survey the disposal willingness and related influential factors of waste mobile phones for consumers in China. In this case, this paper aims to explore the disposal willingness of waste mobile phones and related influential factors for consumers in Shanghai, China.

\section{Research design}

Our survey is designed to capture waste mobile phone disposal willingness and related influential factors of young consumers with ages of 16-28 in Shanghai. The questionnaire contains recycling and disposal willingness, attitudes, subjective norm, perceived control, emotional factors, demographic information, past recycling experience and recycling cognition. The questionnaire is designed based the results of the Theory of Planned Behavior (TPB) [5-6]. We distribute the questionnaires to university students, and other consumers by using information tools, e.g., e-mail and survey webs. 


\section{Results and discussions}

The survey was conducted between October 2013 and May 2014. 1200 questionnaires were distributed, and 785 completed questionnaires were returned, giving a response rate for the survey of $65.42 \%$. With the collected data, the frequency and percentage of the four considered waste mobile phone treatment ways, i.e., storage, recycling, discarding and donation, are reported in Table 1.

Table 1 . The frequency and percentage results

\begin{tabular}{ccc}
\hline Disposal ways & Frequency & Percentage \\
\hline Storage & 620 & $79 \%$ \\
Recycling & 102 & $13 \%$ \\
Discarding & 30 & $3.8 \%$ \\
Donation & 68 & $8.7 \%$ \\
\hline
\end{tabular}

Gender and education are found to have some impacts on waste mobile phone disposal willingness. The corresponding percentages of disposal willingness are displayed in Fig.1 and Fig.2, respectively.

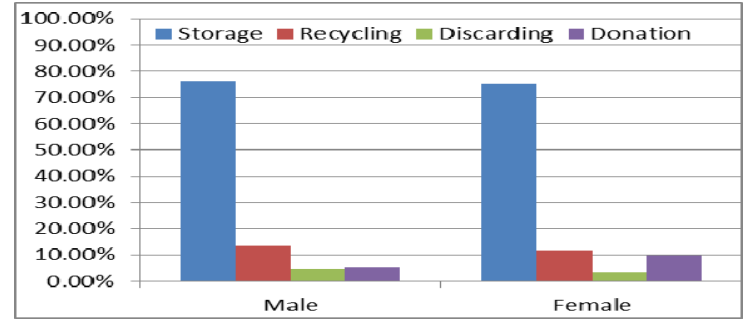

Fig.1. the percentage related to gender

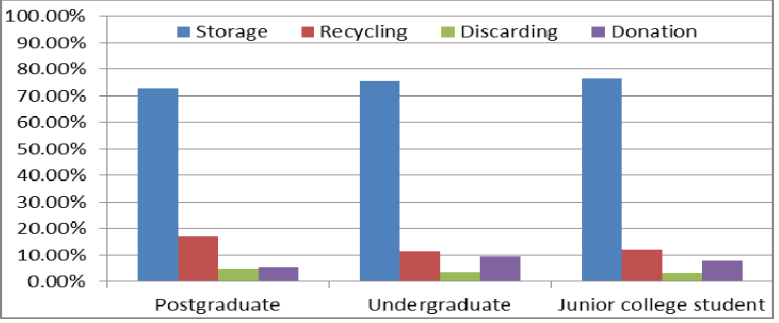

Fig.2. The percentage related to education

As shown in Fig.1, the self-reported results show that $76.26 \%$ male consumers prefer storage of waste mobile phones, which is a little larger than that of female ones $(75.28 \%)$. This is also applied to the recycling and discarding of these two groups, i.e., $13.67 \%$ vs. $11.81 \%$ and 4.68 vs. $3.14 \%$, respectively. However, as for donation, more females $(9.78 \%)$ rather than males $(5.40 \%)$ prefer donating their waste mobile phones to others.

As depicted in Fig.2, evident increasing trend in storage and decreasing trend in discarding related to education from postgraduate ones to junior college ones can be found. Particularly, $72.58 \%$ consumers with postgraduates would like to store their waste mobile phones, while $76.76 \%$ junior college ones prefer this willingness. As for recycling willingness, postgraduate ones take the largest percentage (16.94\%). These results may intuitively indicate that consumers with a higher education level are more likely to recycle their waste mobile phones. It is interesting that, less percentages of postgraduate ones $(5.65 \%)$ and more undergraduate ones $(9.40 \%)$ might donate their waste mobile phones to others than junior college ones $(7.88 \%)$ do.

\section{Influential factors based on Analysis of Variance}

It is assumed that, the influential factors for the consumers' willingness towards each of the four disposal ways may be different. For each way, a respondent can choose "agree" or "disagree" in the questionnaire. As such, all the respondents can be classified into two groups in relation to each way. To identify which of the considered factors exert the significant impacts on the willingness of each way, Analysis of Variance (ANOVA) is used for each variable. The results are reported in Table 2.

Table 2. The results of ANOVA a

\begin{tabular}{ccccc}
\hline Treatment ways & Storage & Recycling & Discarding & Donation \\
\hline Homogeneous & Awareness, Amount, & $\begin{array}{c}\text { Attitude, Control, } \\
\text { Norm, Amount }\end{array}$ & Norm & \\
& Norm & Emotion, & Experience & Experience, Gender, \\
Nonhomogeneous & Experience, ducation, & Emotion & Awareness \\
\hline
\end{tabular}

Note: a Homogeneous indicates that the considered variable for the two groups have an equal mean value, while nonhomogeneous means different mean values; influential factors are all examined at $5 \%$ significance level. 
Based on the results as shown in Table 3, the following findings can be achieved. First, as for storage willingness, self-awareness, amounts of waste mobile phones, subjective norm, education level, emotion and past recycling experience are identified as significant, while others are insignificant. Second, with respect to recycling willingness, attitude, subjective norm, perceived control, amounts of waste mobile phones, emotional factors and past recycling experience are examined significant, while others are not shown significant. Third, regarding discarding willingness, only three factors, i.e., subjective norm, emotion and past recycling experience, are test to be significant in influencing consumers' behaviors. Fourth, it is noteworthy that, in addition to gender and self-awareness, past recycling experience rather than education level is determined as an important factor that affects the consumers' willingness toward donation.

\section{Multiple regression analysis}

To determine which of the considered factors exerts the greatest influence on disposal willingness, multiple regression analysis is further used. To this end, storage, recycling, discarding and donation are treated as dependent variable, respectively. The regression results of variables corresponding to these four treatment ways after iterated operation are shown in Table 3.

Table 3. The regression results ${ }^{\mathrm{a}}$

\begin{tabular}{ccccccccc}
\hline \multirow{2}{*}{ Variables } & \multicolumn{2}{c}{ Storage } & \multicolumn{2}{c}{ Recycling } & \multicolumn{2}{c}{ Discarding } & \multicolumn{2}{c}{ Donation } \\
\cline { 2 - 9 } & Beta & Sig. & Beta & Sig. & Beta & Sig. & Beta & Sig. \\
\hline Attitude & 0.143 & 0.000 & & & 0.027 & 0.015 & & \\
Control & -0.042 & 0.046 & 0.028 & 0.080 & & & & \\
$\quad$ Norm & & & & & & & & \\
Experience & -0.249 & 0.000 & 0.251 & 0.0000 & 0.048 & 0.0000 & -0.026 & 0.100 \\
Education & -0.111 & 0.000 & & & & & & \\
Emotion & & & -0.186 & 0.029 & 0.004 & 0.010 & & \\
$\quad$ Gender & -0.098 & 0.003 & & & & & -0.035 & 0.096 \\
Awareness & -0.027 & 0.058 & & & & & -0.026 & 0.0000 \\
Income & 0.044 & 0.034 & & & -0.003 & 0.012 & & \\
Age & -0.204 & 0.049 & & & & & 0.053 & 0.018 \\
Amount & & & & & & & 0.000 \\
\hline
\end{tabular}

Note: ${ }^{A n}$ adjusted $\mathrm{R}^{2}$ for storage, recycling, discarding and donation are $0.207,0.088,0.04$ and 0.032 , respectively.

As shown in Table 3, we can find that, with respect to storage, past recycling experience and education have relatively higher negative coefficients and attitude has relatively positive coefficient than other variables have, and these three variables are all statistically significant. This indicates that past recycling experience, education and attitude play important roles in influencing consumers' storage willingness in Shanghai. As for recycling, three variables are estimated to be significant, i.e., perceived control at the $10 \%$ significance level, past recycling experience at the $1 \%$ significance level and emotion at the 5\% significance level. Among these three variables, past recycling experience has a much higher positive coefficient and emotion has a relatively higher negative coefficient. With regard to discarding, although there are some variables like past recycling experience estimated as significant, their coefficients are all very low, which implies that the impacts of these variables are all very slight. Similarly, regarding donation willingness, the four significant variables, i.e., past recycling experience, self-awareness, gender and amounts of waste mobile phones, are all examined to have very low coefficients.

\section{Further discussions}

The above mentioned results indicate that, young consumers prefer storing their waste mobile phones, and the willingness to participate in recycling is still at a lower level. Additionally, a few consumers will donate their waste mobile phones to other to some extent, which may extend the use life of the corresponding mobile phones. This behavior, generally, should be encouraged in practice. However, 
there still exist very few of them that would like to discard their waste mobile phones as wastes, which should be eliminated, for that this in turn may directly result in environmental pollution.

To further explore the influential factors that affect disposal willingness of consumers, we examine the impats recycling price and recycling convenience. The correlation analysis results show that, recycling price has significantly positive impacts on the willingness of recycling of consumers; and recycling inconvenience may have significantly positive impacts on discarding willingness for consumers. This may indicates that, given a certern recycling price or multiple recycling approaches, the recycling amounts of waste mobile phones might be improved.

\section{Conclusions and policy suggestions}

This study examines the waste mobile phone disposal willingness for young consumers and realted influential factors in Shanghai, China. Four disposal ways, i.e., storage, recycling, discarding and dontation, are explored. The results show that, most of consumers are willing to store their waste mobile phones, while less of them prefer recycling waste moble phones. Some of them will donte waste mobile phones to others and the remaining may disard waste mobile phones. Among the four considered disposal ways, recycling is an encouraged behavior, and donation is another one. Particularly, with respect to recycling, we find that gender, education, past recycling experience, emotional factors, recycling price and reclycing convenience are examined to signifiacntly affect the willingness of young consumers. Thus, improving the education level, giving reasonable recycling price, and ehancing recycling convenience (e.g., setting more recycling points) may improve recycling rates of waste mobile pones.

\section{Acknowledgements}

This research was partially supported by projects of Humanities and Social Sciences of Chinese Ministry of Education (no.10YJC630007).

\section{References}

[1] Ong Ondo, F.O., Williams, I.D., Mobile phone collection, reuse and recycling in the UK, Waste Management, 31 (2011) 1307-1315.

[2] Wang, Z., Zhang, B., Yin, J., Zhang, X., Willingness and behavior towards e-waste recycling for residents in Bejing City, China, Journal of Cleaner Production, 19 (2011) 977-984.

[3] Bains, N., Goosey, M., Holloway, L., Shailer, M., An integrate approach to electronic waste (WEEE) recycling: Socio-economic Analysis Report, Rohm and Hass Electronic Materials Ltd., UK, 2006.

[4] Yu, J., Williams, E., Ju, M., Shao, C., Managing e-waste in China: policies, pilot projects and alternative approaches, Resources, Conservation and Recycling, 54 (2010) 991-999.

[5] Ajzen, I., The theory of planned behavior, Organ Behave Hum Processes, 50 (1991) 179-211.

[6] Tong let, M., Phillips, P.S., Bates, M.P., Determining the drivers for householder pro-environmental behavior: waste minimization compared to recycling, Resources, Conservation and Recycling, 42 (2004) 27-48. 